\title{
AN INNOVATIVE METHOD FOR FORMING BALLS FROM SCRAP RAIL HEADS
}

\author{
Zbigniew Pater'1, Janusz Tomczak' ${ }^{1}$, Tomasz Bulzak¹
}

Department of Mechanical Engineering, Lublin University of Technology, 36 Nadbystrzycka St., 20-618 Lublin, Poland, e-mail: z.pater@pollub.pl, j.tomczak@pollub.pl, t.bulzak@pollub.pl

Received: 2016.04.08

Accepted: 2016.07.04

Published: 2016.09.01

\begin{abstract}
The paper describes a new method for forming grinding media balls from scrap rail heads. This forming method involves the following operations: cutting the rail head to the desired length combined with lateral pressing of the produced workpiece; flashless die forging and sizing of balls in a helical impression. The proposed method was verified by numerical simulation which involved the modeling of a forming process for producing $80 \mathrm{~mm}$ diameter balls. As a result of the modeling, it was possible to examine the changes in the workpiece shape during each forming operation, the variations in loads and torques, as well as the distribution of temperatures enabling performing another forming operation, i.e. quenching. The results confirm that the designed method can be used to produce balls.
\end{abstract}

Keywords: die forging, balls, FEM.

\section{INTRODUCTION}

There are numerous industrial methods for producing balls for rolling bearings and ball mill grinding media. They include die machine forging and press forging, as well as cross and skew rolling.

Small balls are produced by machine forging. This process is based on the use of steel bars that have a smaller diameter than that of formed balls. Larger diameter balls are usually formed from steel circular-section billets with higher carbon and manganite contents by die forging using friction drive presses. The forging process is followed by flash trimming performed using eccentric presses [1].

Skew rolling is a process which ensures the highest efficiency in the production of balls. A single ball is produced during one rotation of the rolls. With this method it is possible to produce within one minute 160 balls that are $30 \mathrm{~mm}$ in diameter or 40 balls that are $120 \mathrm{~mm}$ in diameter. Balls are formed using skew rolling mills equipped with two rolls, each roll having single grooves serrated over the screw line (usually over a length of 3.5 of the coil). The axes of the rolls are inclined to the axis of the workpiece (bar) at an angle of $3 \div 7^{\circ}$. During rolling the rolls are rotated in the same direction, while the workpiece is rotated in the opposite direction to that of the rolls. In this process, too, balls are formed from circular section bars $[2,3]$.

In addition, there are also forming methods based on the cross rolling technique which uses wedge-shaped tools. Rotated in mutually opposite directions, these tools sink deeper and deeper into the billet and hence form a necking separating the balls; the balls are cut off in the final stage of the process. Considering the many cross rolling methods for producing balls [4-8], particular attention should be paid to the method $[7,8]$ wherein scrap rail heads are used a billet. This method involves the use of two-segment flat tools. First of all, the billet (rail head) is formed between flat tools to produce a bar with a circular section. After that, the produced bar is moved to the other segment of the tools, where it is formed into balls on the return motion of the rolling mill. 
A characteristic of this rolling method is lack of idle run, which affects rolling efficiency. This method enables producing balls with a diameter of up to $60 \mathrm{~mm}$.

This paper presents a new method for flashless forming of balls for grinding media from rail heads, as this method enables producing larger balls than it is possible with the above rolling process. This method is based on flashless forging followed by the sizing of the balls in a helical impression. The proposed solution is verified by numerical modeling based on finite element method.

\section{DESIGN OF THE METHOD FOR FORMING BALLS FROM SCRAP RAIL HEADS}

The proposed method for forming balls, in particular large balls, from scrap rail heads consists in preheating the semi-finished product 7 to a hot-forming temperature. Next, the preheated semi-finished product 7 is moved with a constant velocity $v_{1}$ of the forming rolls $1 \mathrm{a}$ and $1 \mathrm{~b}$ to the work space formed by the lower die 2 and the upper die 3 which form a die impression with a hexagonal section (Fig. 1). After that, the upper die 3 is moved with a constant velocity v2 towards the lower die 2, and the end section of the semi-finished product 7 undergoes reduction in the hexagonal impression to form a section of the bar 8 with a hexagonal section. After that, the semi-finished product 7 is again moved to the bumper 6 . The semi-finished product 7 is moved by a constant distance L; after that the semi-finished product 7 is stopped. Next, the upper die 3 is again moved with the constant velocity $v_{2}$ towards the lower die 2 and another section of the

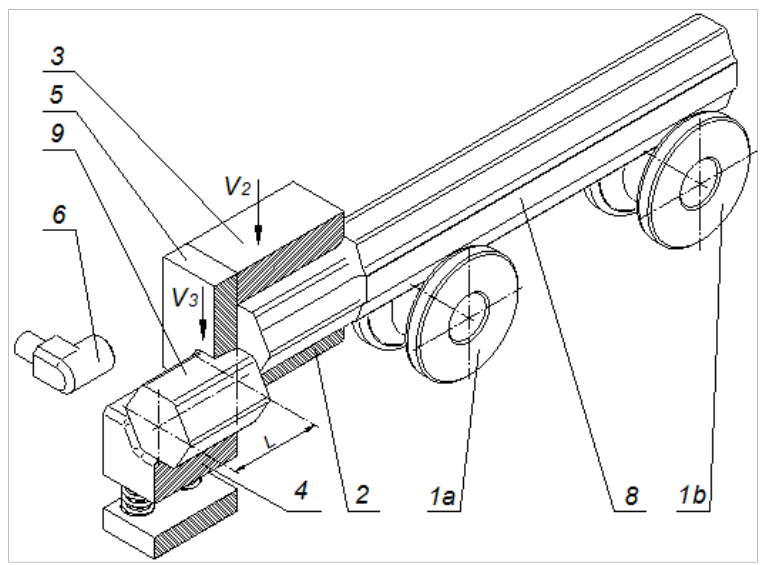

Fig. 1. Splitting and lateral pressing of billet - scrap rail head (described in the text)

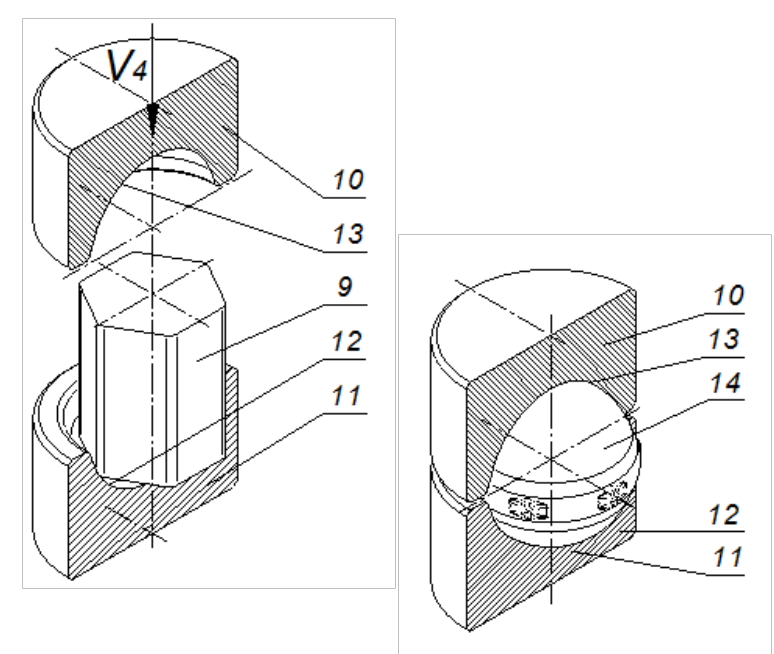

Fig. 2. Schematic design of a die forging process for producing semi-finished balls from hexagonal billet (described in the text)

semi-finished product 7 is reduced in the hexagonal impression. Simultaneously, the forming cutter 5 is moved with a constant velocity $v_{3}$ towards the lower die 2; the end section of the hexagonal-section bar 8 is cut off from the semi-finished product 7 to produce the billet 9 in the form of a hexagonal-section bar, the volume of which is equal to that of the ball 15 . Next, the billet 9 is placed between the upper forming die 10 and the lower forming die 11 (Fig. 2). The upper forming die 10 and the lower forming die 11 have the concave surfaces 12 and 13 with a spherical profile corresponding to the profile of the ball 15. After that, the upper forming die 10 is moved towards the lower forming die 11 with a constant velocity v4 to form the semi-finished ball 14 described by an irregular shape. Next, the semi-finished product 14 is transferred to the helical die impression

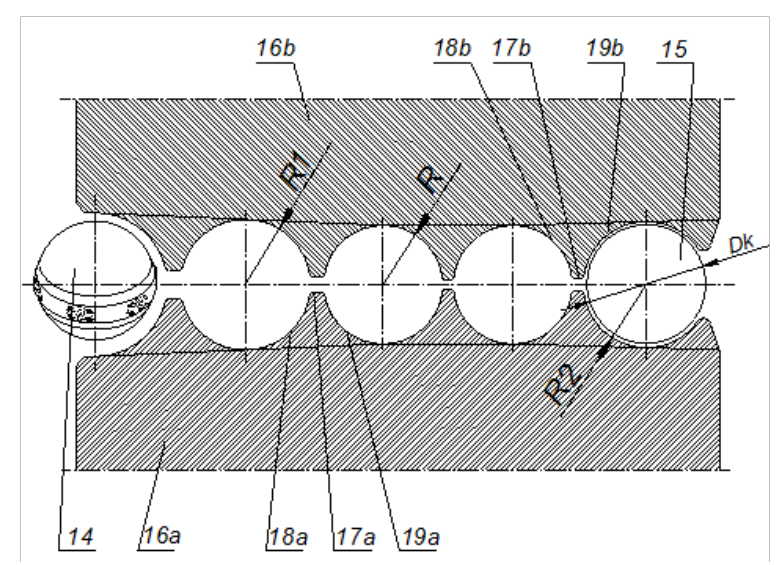

Fig. 3. Section of the helical impression for sizing the ball (described in the text) 
(Fig. 3) which is formed by helical protrusions $17 \mathrm{a}$ and $17 \mathrm{~b}$ described by the concave lateral surfaces 18a, 18b, 19a and 19b and located on the surfaces of the rolls $16 \mathrm{a}$ and $16 \mathrm{~b}$. After that, the rolls $16 \mathrm{a}$ and $16 \mathrm{~b}$ are rotated in the same direction with the same velocity to size the shape of the ball 14 , which leads to the production of the ball 15 . The rolls $16 \mathrm{a}$ and $16 \mathrm{~b}$ have a three-zone design enabling the sizing of the ball 14 . The first zone contains impressions described by a radius $R 1$ which is higher than the radius of the ball 15 . The second zone contains helical impressions whose radius $R$ is half the diameter $D k$ of the ball 15 . The third zone of the conical surface contains impressions described by a radius $R 2$ which is higher than that of the ball 15 .

The designed method for producing balls was filed for patent protection with the Patent Office of the Republic of Poland [9]. An advantage of this invention is that it enables forming balls with larger dimensions compared to the size of balls produced by a rolling process in which they are directly formed from scrap rail heads. The invention will increase the efficiency of producing balls compared to standard die forging processes. It will also lead to reduced energy and material consumption due to the removal of allowance for flash as well as the reduced number of technological operations.

\section{NUMERICAL MODELING OF THE FORMING PROCESS FOR $80 \mathrm{MM}$ DIAMETER BALLS}

The designed method was verified numerically by finite element method owing to high costs of the instruments. The simulation involved the modeling of a process for forming $80 \mathrm{~mm}$ diameter balls from a rail head described by a length of $92.5 \mathrm{~mm}$. The authors of this paper have considerable experience in performing numerical modeling of different metal forming processes, and the applied simulation software, Simufact.Forming, enables obtaining results which show a good agreement with experimental findings [10-15].

The modeling of the forming process for balls did not include the operation of cutting the rail head to the desired length of $92.5 \mathrm{~mm}$. The computations were made for the following operations: the lateral pressing of the billet, the forging and sizing of the ball in the helical impression. The results of each preceding operation were used as input data for the subsequent operations. The ball was assigned the properties of rail steel grade R200, the flow stress of which is described by the following dependence:

$$
\begin{aligned}
\sigma_{p}= & 9898,75 \cdot \varphi^{0,111} \cdot \exp (-0,594 \cdot \varphi) . \\
& \cdot \dot{\varphi}^{0,227} \cdot \exp (-0,00415 \cdot T)
\end{aligned}
$$

where: $\sigma_{p}-$ is a flow stress, MPa;

$\varphi$ - is an effective strain;

$\varphi-$ is a strain rate, $\mathrm{s}^{-1}$,

$T-$ is a temperature, ${ }^{\circ} \mathrm{C}$.

Prior to forming, the entire billet was preheated to a temperature of $1100^{\circ} \mathrm{C}$, while the temperature of the tools during forming was maintained constant at $200{ }^{\circ} \mathrm{C}$. The transfer of heat between the metal and the tools was described the a heat transfer coefficient set to $10 \mathrm{~kW} / \mathrm{m}^{2} \mathrm{~K}$.

In the lateral pressing of the rail head (Fig. 4), the forming is performed in a hexagonal die impression (inscribed into a circle with a diameter of $67 \mathrm{~mm}$ ), the edges of which are described by a radius of $5 \mathrm{~mm}$. The upper tool is rotated with a constant velocity of $50 \mathrm{~mm} / \mathrm{s}$, and the friction factor on the active surfaces of the tools is set to 0.7 , which reflects poor lubrication conditions.

Due to the application of lateral pressing the billet has a more compact shape. Nonetheless, as shown in Figure 4, the cross section of the workpiece is not uniform over the entire length. The cross section is larger in the centre and smaller on the ends where the metal can flow along the die impression. Moreover, lateral pressing does not lead to obtaining the desired hexagonal section. Due to the irregular shape of the billet (rail head has a remainder of the removed neck on one side), the cross section of the semi-finished product after lateral pressing has a pentagon-resembling shape, which will undoubtedly ensure the accuracy of the ball produced by die forging.

The load applied in lateral pressing is small. According to the data given in Figure 5, the maximum load is $0.5 \mathrm{MN}$. This means that there should be no problems with combining the cutting and lateral pressing processes which can be performed using small loads.

The subsequent forming operation, i.e. die forging, is shown in Figure 6. This operation is performed using dies that have identical spherical impressions (with a radius of $40 \mathrm{~mm}$ ) with a conical exit (with an angle of $25^{\circ}$ ) to the die parting surface. The results of the numerical simulation (performed at the identical parameters as those applied in lateral pressing) demonstrate that after 


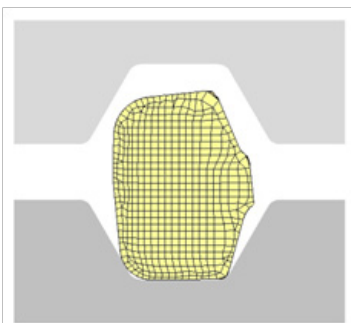

Starting position

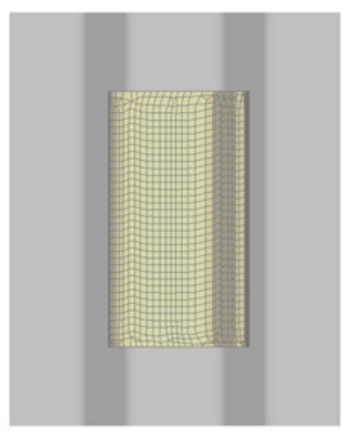

Fig. 4. Lateral pressing to increase the density of billet (scrap rail head) used for forming an $80 \mathrm{~mm}$ diameter ball by die forging

forging the whole of the metal remains in the die impression and does not come up to the surface of the die parting. Nonetheless, the ball produced by this process has visible shape defects (Fig. 7). More specifically, the upper and lower surfaces exhibit flattening, while the profile of the cross section of the ball in the plane of the die parting resembles a pentagon with rounded edges. The

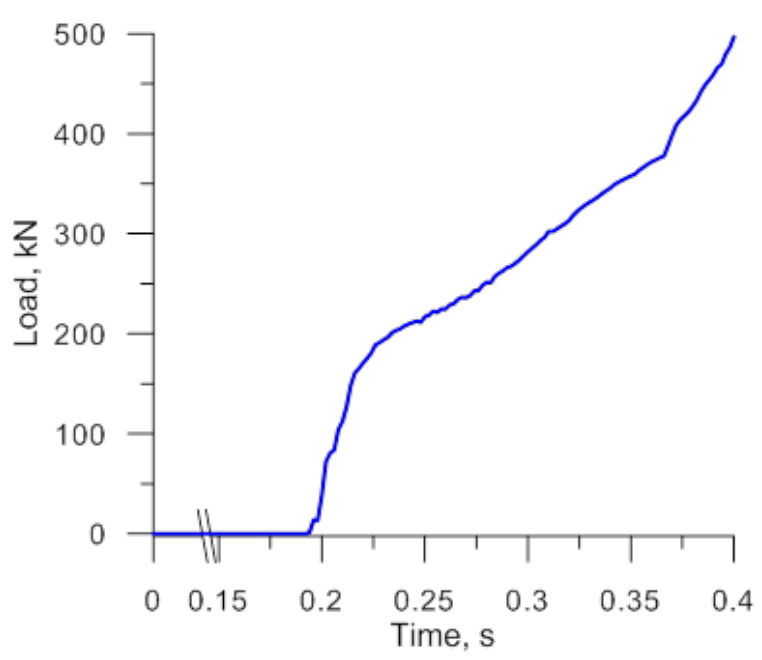

Fig. 5. Variations in the load during the lateral pressing of a scrap rail head

above inaccuracies result from the shape of the billet produced in lateral pressing.

The proposed forging process is characterized by lower energy consumption, as it can be seen from the diagrams illustrating the variations in load shown in Figure 8. The maximum load in this forming operation is very small and amounts only to $0.7 \mathrm{MN}$. This results from the occurrence

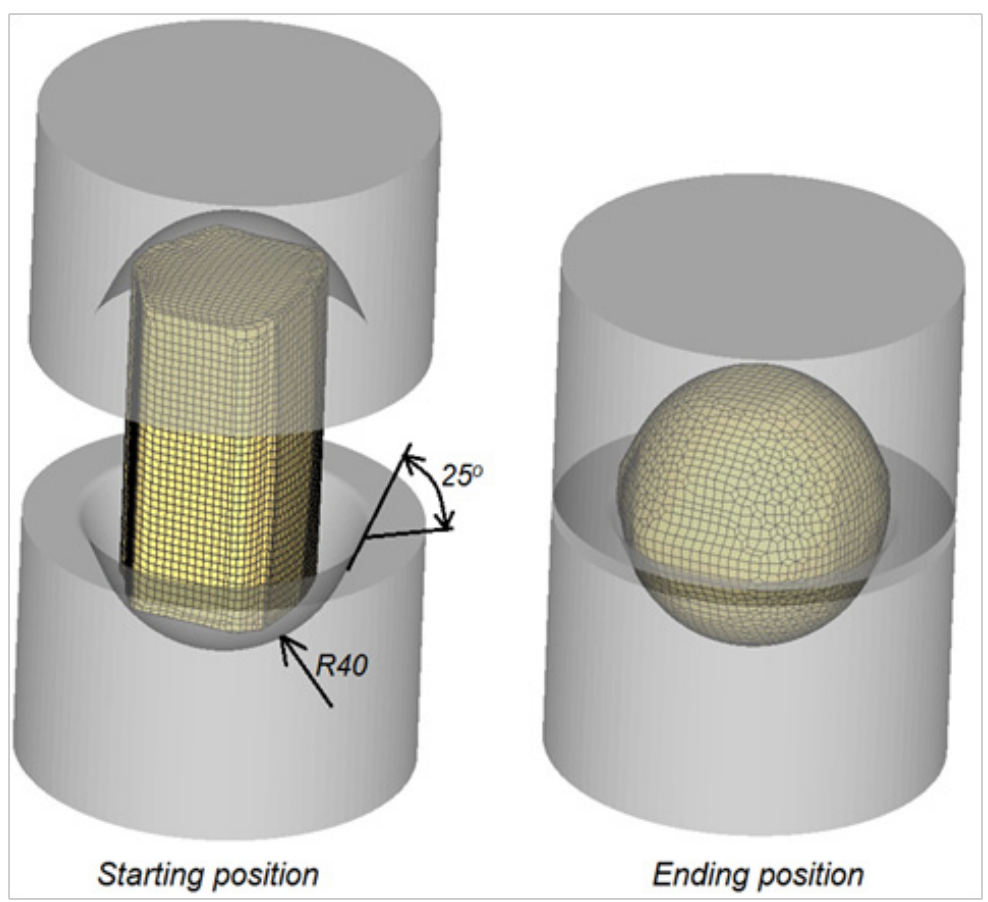

Fig. 6. Schematic design of a die forging process for producing an $80 \mathrm{~mm}$ diameter ball formed from a scrap rail head 


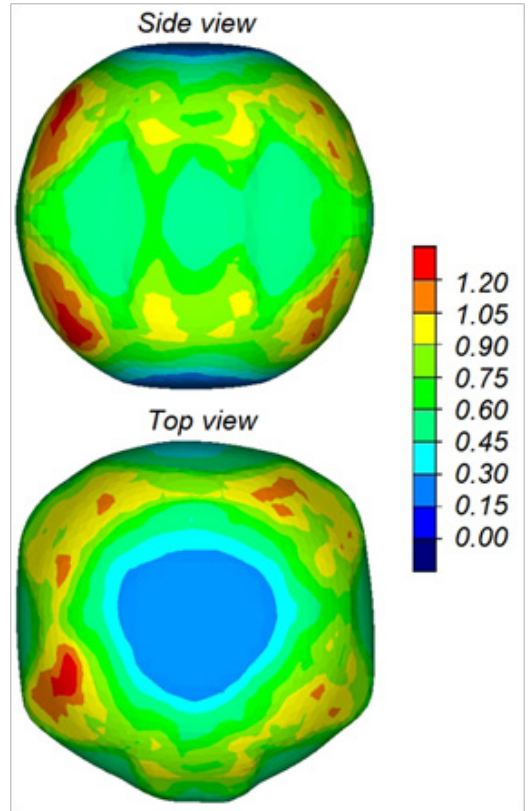

Fig. 7. Shape of a ball formed from a scrap rail head and the distribution of effective strains

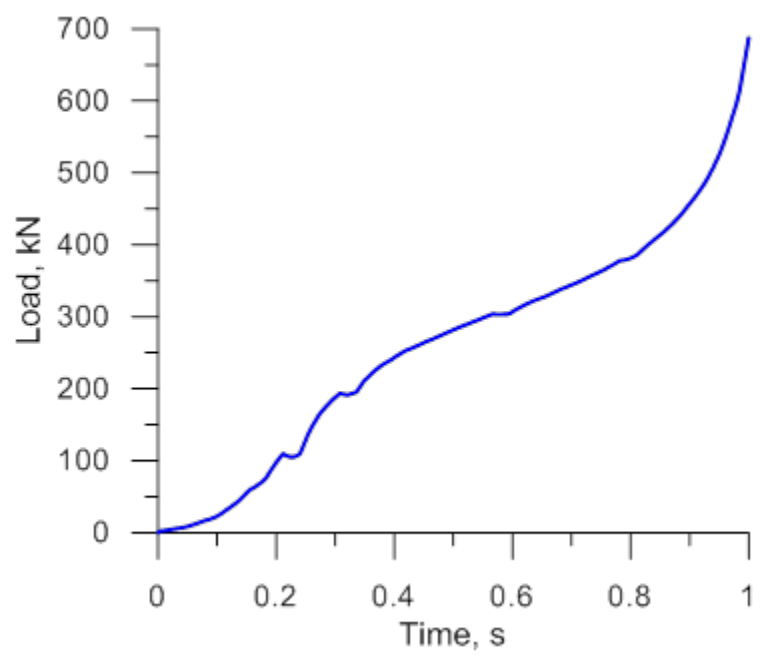

Fig. 8. Loads in the forging process for an $80 \mathrm{~mm}$ diameter ball

of upsetting, which - in terms of loads - is the most advantageous type of metal flow.

During forging, the metal undergoes local cooling due to contact with the tools. The temperature drops there even below $860^{\circ} \mathrm{C}$ (Fig. 9). However, the observed drop in temperature occurs only on the surface, while the temperature of the metal inside the ball is still high - it is lower than the billet's temperature only by several degrees. It can therefore be assumed that the temperature in the cooled surface layers of the metal will increase shortly due to thermal conduction.

The final forming operation, i.e. sizing, is shown in Figure 10. It involves the use of two

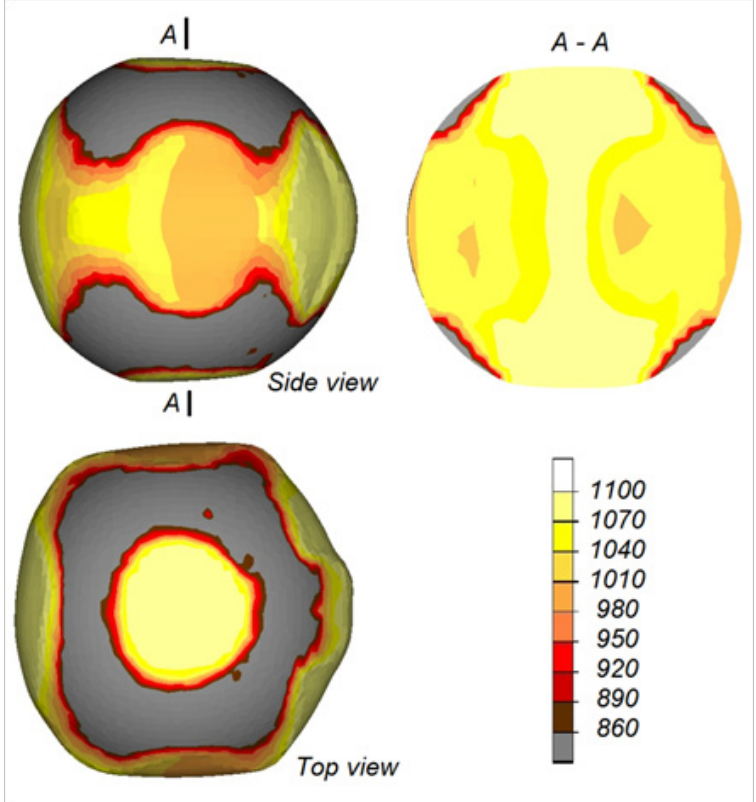

Fig. 9. Temperature (in ${ }^{\circ} \mathrm{C}$ ) in a semi-finished ball formed from a scrap rail head

rolls (each with a nominal diameter of $400 \mathrm{~mm}$ ) provided with helical impressions of varying diameters (Ø90 $\mathrm{mm} \rightarrow \varnothing 80 \mathrm{~mm} \rightarrow \varnothing 82 \mathrm{~mm})$ and rotated in the same direction with the velocity set to $30 \mathrm{rev} / \mathrm{min}$. Besides the rolls, the sizing operation involves the use of two guiding blades to prevent the ball from being pushed out from the forming zone and a sleeve for feeding the billet (i.e. balls produced by die forging).

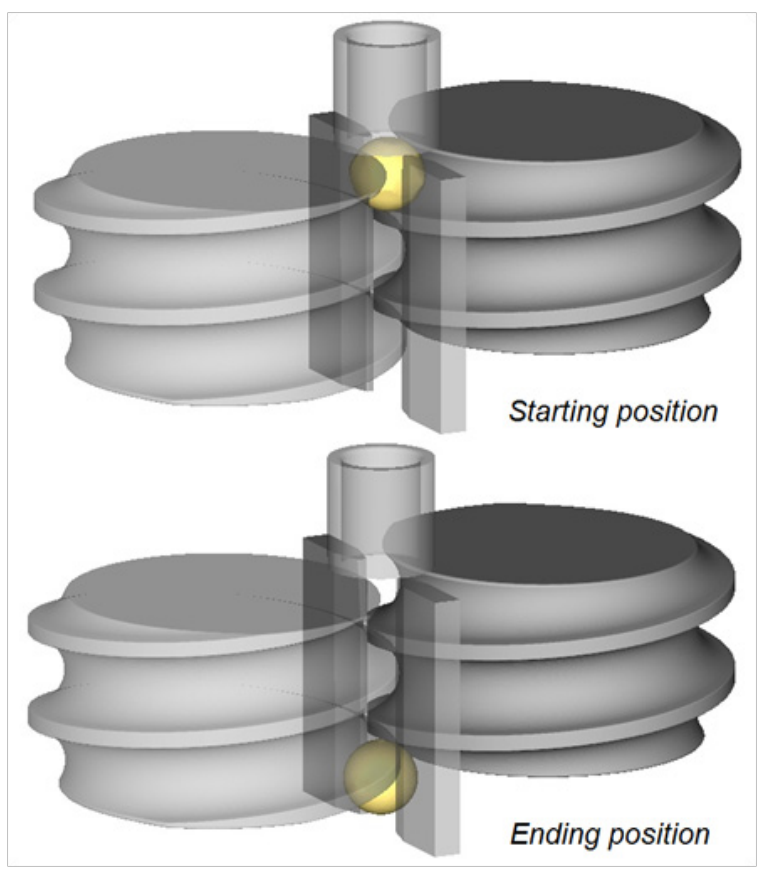

Fig. 10. Design of the sizing process for removing shape defects of a ball formed from a scrap rail head 


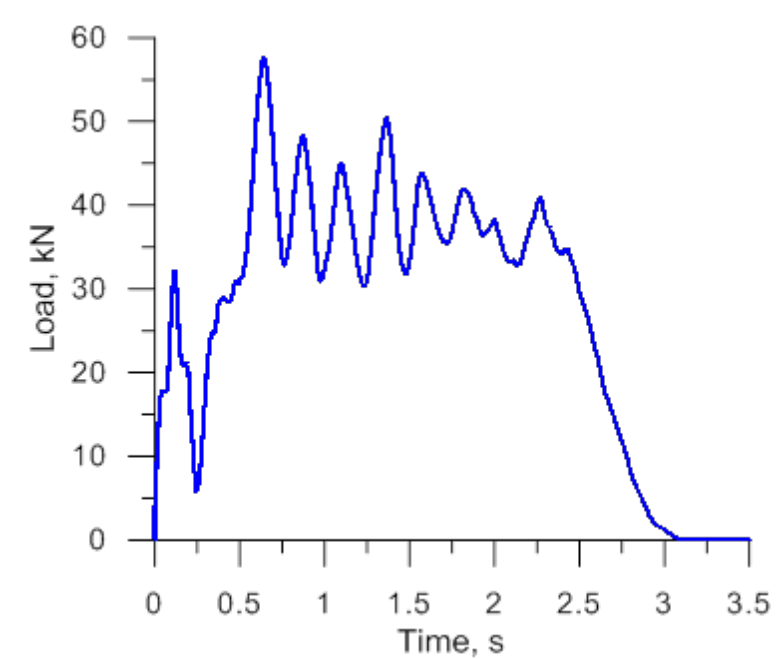

Fig. 11. Radial loads on the helical roll used in the sizing of $80 \mathrm{~mm}$ diameter balls

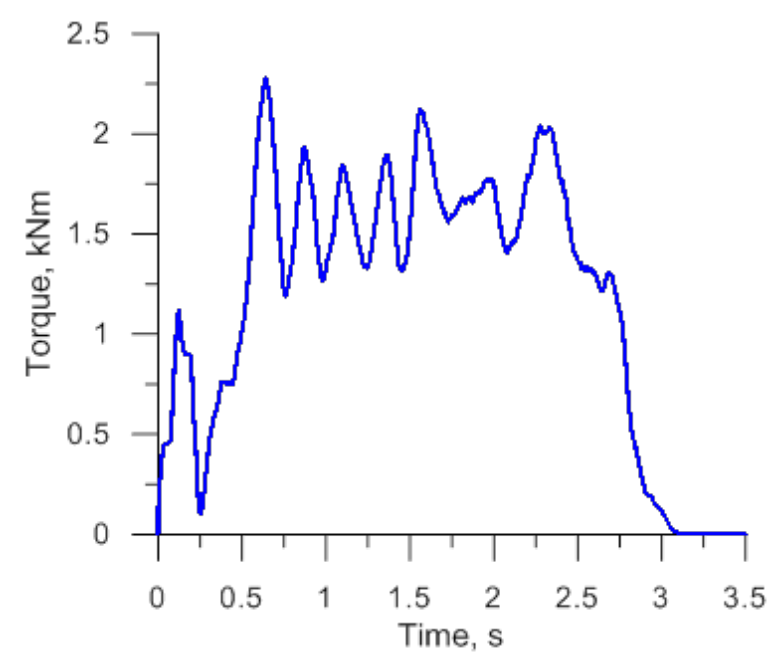

Fig. 12. Torque on the helical roll used for the sizing of $80 \mathrm{~mm}$ diameter balls

The numerical results demonstrate that the sizing operation proceeds correctly. Importantly, this operation does not require high loads (Fig. 11) or torques (Fig. 12), the variations in which result from the irregular removal of shape defects. Given the small magnitude of loads and torques necessary for sizing one ball, the process can be accelerated. This can be done by feeding another ball into the helical impression before the ball being sized at the moment has left the work space of the rolls. As can be seen in Figure 13, the ball after sizing has the desired shape despite the fact that the post-forging shape defects have not been entirely removed and slight flattening is still visible. These defects are however insignificant when it comes to the forming of balls for grinding media, as the diameter tolerance here is $\pm 3 \mathrm{~mm}$.
The strains produced during sizing are local. The local diameter reduction occurs where the dimension of the ball exceeds the required value, which leads to a non-uniform distribution of effective strains (also shown in Figure 13).

It is worth drawing attention to the distribution of the temperature of the balls after the sizing operation. According to Figure 14, the temperature ranges between $920^{\circ} \mathrm{C}$ and $1070{ }^{\circ} \mathrm{C}$, which is much higher than the recommended quenching temperature, i.e. $860^{\circ} \mathrm{C}$. For this reason, prior to quenching, the ball should be kept in free air in

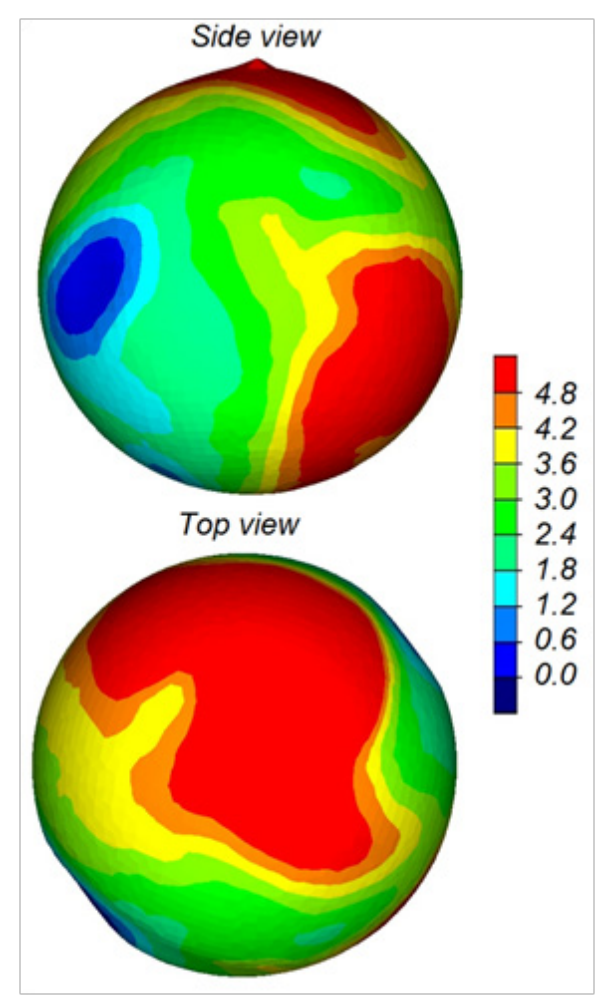

Fig. 13. Effective strains in a ball after removal of shape defects by sizing

order to stabilize and decrease its temperature to the recommended value.

\section{CONCLUSIONS}

The results demonstrate that the proposed method enables formation of large balls (with diameter $80 \mathrm{~mm}$ and greater) from scrap rail heads. The method has the following advantages:

- the forming process is flashless;

- the methods ensures satisfactory accuracy of balls for grinding media;

- individual forming operations (lateral pressing, die forging and sizing) are performed at low 


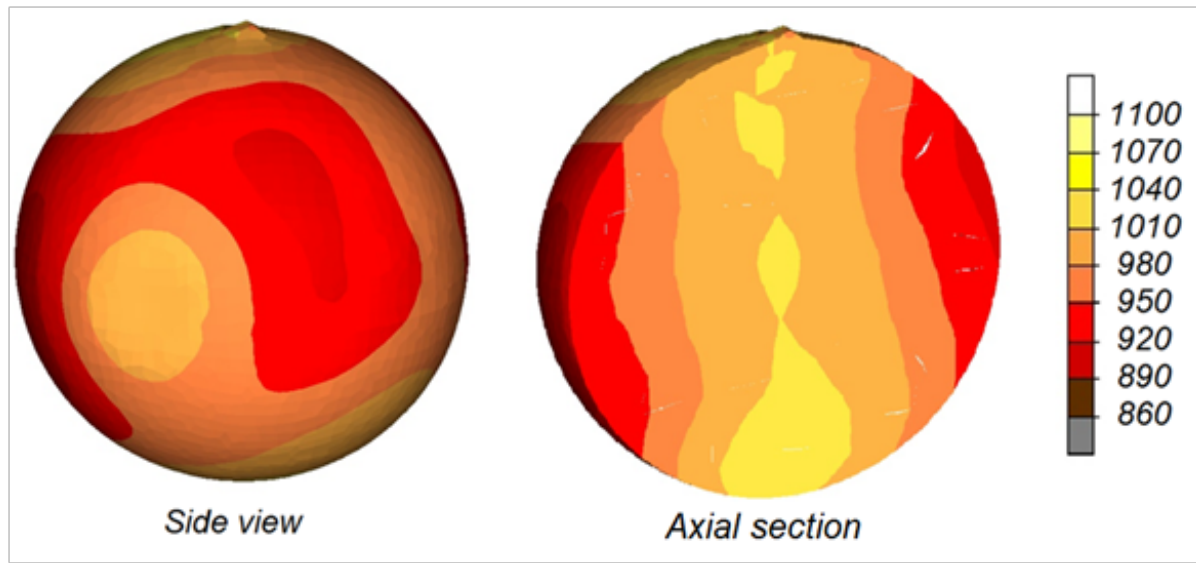

Fig. 14. Ball temperature (in ${ }^{\circ} \mathrm{C}$ ) after sizing in a helical impression

loads and torques, which results in low energy consumption of the production process;

- the process is simple and easy to automate;

- the temperature of produced balls enables performing another forming operation, i.e. quenching.

\section{Acknowledgements}

The study is part of the agreement no. INNOTECH-K3/IN3/12/226286/NCBR/14 for the execution and financing of projects within the framework "INNOTECH" Programme in the INTECH programme path.

\section{REFERENCES}

1. Luty W.: Metaloznawstwo i obróbka cieplna stali łożyskowych. Wyd. WNT, Warszawa 1980.

2. Pater Z., Tomczak J.: Walcowanie śrubowe kul do młynów kulowych. Wyd. Politechniki Lubelskiej, Lublin 2012.

3. Pater Z., Tomczak J., Bartnicki J., Lovell M.R., Menezes P.L.: Experimental and numerical analysis of helical-wedge rolling process for producing steel balls. International Journal of Machine Tools \& Manufacture, 67, 2013, 1-7.

4. Pater Z., Gontarz A., Weroński W.: Cross-wedge rolling of balls. Steel Research International. "Special edition: Metal Forming 2008”, 1, 2008, 369-374.

5. Pater Z.: Multi-wedge cross rolling of balls. Journal of Iron and Steel Research International, 20 (10), 2013, 46-50.
6. Pater Z.: New methods of steel ball rolling. International Journal of Materials \& Product Technology, 47 (1/2/3/4), 2013, 12-22.

7. Pater Z.: Method for cross rolling of products in the shape of balls, in particular out of scrap railway rail heads. EU Patent nr EP2537605 B1, 2014.

8. Pater Z.: Method for transverse rolling of ball products, in particular out of scrap railway rail heads, using flat tools. EU Patent nr EP2540409 B1, 2014.

9. Pater Z., Tomczak J.: Sposób kształtowania kul. Zgłoszenie patentowe P.403989, 2013.

10. Pater Z., Tomczak J., Bulzak T.: Numerical analysis of the skew rolling process for main shafts, Metalurgija, 54 (4), 2015, 627-630.

11. Pater Z.: Analysis of the Helical-Wedge Rolling Process for Producing a Long Stepped Shaft. Key Engineering Materials, 622-623, 2014, 893-89.

12. Qiana D., Maoa H., Dengb J., Yue J.: Processing optimization for large spherical valve body based on FE simulation. Procedia Engineering, 81, 2014, 2481-2487.

13. Cao Q., Hua L., Quian D.: Finite element analysis of deformation characteristics in cold helical rolling of bearing steel-balls. Journal of Central South University, 22 (2), 2015, 1175-1183.

14. Qian D., Pan Y.: 3D coupled macro-microscopic finite element modelling and simulation for com $\neg$ bined blank-forging and rolling process of alloy steel large ring. Computational Materials Science, 70, 2013, 24-36.

15. Berti G.A., Quagliato L., Monti M.: Set-up of radial-axial ring-rolling process: Process worksheet and ring geometry expansion prediction, International Journal of Mechanical Sciences, 99, 2015, 58-71. 